\title{
Terrores guajiros. Lecturas transversales entre las políticas de la identidad, la violencia masiva y la economía transnaciona ${ }^{1}$
}

\section{Guajiro terrors. A cross-reading through the policies of identity, the mass violence and transnational economy}

\author{
Carlos Arturo SALAMANCA \\ Universidad Nacional de Rosario (Argentina) \\ salamanca.carlos@gmail.com
}

Recibido: 28 de enero de 2014

Aceptado: 24 de febrero de 2015

\section{Resumen}

A partir de las experiencias recientes de los indígenas wayúu de La Guajira colombiana, analizo las formas en que las prácticas de la memoria en situaciones de violencia masiva se entrecruzan con las políticas del multiculturalismo y la expansión de la minería transnacional. Describo, en primer lugar, el contexto actual de La Guajira y la expansión de la economía transnacional. A continuación hago uso del concepto de mediaciones para analizar algunas de las formas en que los pueblos indígenas vienen tramitando sus experiencias de violencia masiva. En la tercera parte analizo los acontecimientos de violencia masiva deteniéndome en sus diversas formas de articulación con otros campos. En la última parte, propongo una lectura transversal de dichos campos evidenciando las razones por las que la noción de mediaciones de memoria permite abordar los acontecimientos de violencia sin que esto signifique quedar atrapado en la fenomenología del acontecimiento o circunscripto a las gramáticas de la cultura.

Palabras clave: espacio; violencia; wayuu; memoria; mediaciones; economía transnacional.

\begin{abstract}
Focusing on the recent experiences of the Wayuu indigenous people of Colombian Guajira, I analyze the ways in which memory practices in situations of mass violence are intertwined with the politics of multiculturalism and expansion of transnational mining. In the first part I describe the current context of La Guajira and the expansion of the transnational economy. In the second part I use the concept of mediations to analyze some of the ways in which indigenous peoples have been processing their experiences of mass violence. In the third part I analyze the events of mass violence and various forms of articulation with other fields.

${ }^{1}$ Versiones preliminares de este trabajo fueron expuestos en el seminario "Espacio, historia y poder", que he realizado en varias oportunidades entre el 2010 y el 2014. Mi agradecimiento a los participantes que, con sus preguntas y comentarios, enriquecieron estas reflexiones. Agradezco también a Catalina Cortés Severino, Claudia Puerta, Rosario Espina, y Cesar Ceriani y a los lectores anónimos de la revista por sus lecturas atentas a versiones preliminares de este manuscrito.
\end{abstract}


In the last part, I propose a cross-reading of these fields, trying to show why the notion of mediations of memory helps to analyze the acts of violence without getting caught up in the phenomenology of the event or circumscribed to the grammars of culture.

Keywords: space; violence; wayuu; memory; mediations; transnational corporations.

Referencia normalizada: Salamanca, C.A. (2015) Terrores guajiros. Lecturas transversales entre las políticas de la identidad, la violencia masiva y la economía transnacional, en Revista de Antropología Social 24, 287-315.

SUMARIO: 1. Tiempos extraños en una región de frontera. 1.1. Los amigos repentinos. 1.2. Terror, dinero y circuitos de ilegalidad. 2. Las mediaciones de memoria y la búsqueda de espacios habilitantes. 3. Enfrentando las múltiples violencias. 3.1. Un escenario complejo. 3.2. Empresas y mercados. 3.3. Minería, espectáculo y la creación de un mundo nuevo. 3.4. Narrativas de la cultura y de la naturaleza en objetos híbridos. 3.4.1. Gestas ecológicas. 4. Una lectura transversal y la pregunta por las articulaciones: a modo de conclusión. 3.4.2. Iwo'u yaa: "las estrellas que anuncian la llegada de la primavera". 5. Referencias bibliográficas.

A partir de las experiencias recientes de los indígenas wayúu de La Guajira colombiana, analizo las formas en que las prácticas de la memoria en situaciones de violencia masiva se entrecruzan con las políticas del multiculturalismo y la expansión de la minería transnacional. Describo, primero, el contexto actual de La Guajira. A continuación analizo algunas de las formas en que los pueblos indígenas vienen tramitando sus experiencias de violencia masiva del pasado reciente. En la tercera parte analizo algunas formas en que los acontecimientos de violencia masiva se articulan con otros campos. Finalmente, propongo una lectura transversal de dichos campos intentando demostrar la utilidad de abordar los acontecimientos de violencia sin quedar atrapado en la fenomenología del acontecimiento o circunscripto a las gramáticas de la cultura.

Este trabajo no es el resultado de la observación etnográfica. Para las descripciones que aquí se presentan utilizo las descripciones hechas por los mismos wayúu, antropólogos, agencias del Estado y medios de comunicación. En esta primera parte de mi investigación me interesan las formas en que las prácticas, dinámicas y experiencias en La Guajira se (re)presentan en el espacio público, y los discursos que se crean sobre ellas, pues me interesa resaltar que, la búsqueda de inserción en esferas públicas implica un proceso de redefinición.

\section{Tiempos extraños en una región de frontera}

\subsection{Los amigos repentinos}

Desde hace unos veinte años los indígenas wayúu, habitantes en la región del Caribe en la frontera binacional colombo-venezolana ${ }^{2}$, viven una situación extraña.

${ }^{2}$ Los wayúu son uno de los 81 grupos étnicos que actualmente existen en Colombia. A él pertenecen aproximadamente 148.000 de los 700.000 indígenas oficialmente reconocidos, 
Empresas multinacionales y nacionales del turismo, de la energía limpia y de la explotación del petróleo, gas y carbón, bautizan sus proyectos con sus nombres en wayūnaiki (idioma wayúu tradicional), decoran sus documentos ejecutivos con diseños similares a los de sus mochilas, y en sus comunicados subrayan la importancia del medio ambiente y de las tradiciones culturales de la región. En los encuentros con ejecutivos y altos representantes, son recurrentes los discursos que, reconociendo la sabiduría ancestral de los Guajiros tradicionales, hablan de la llegada de oportunidades históricas; también abundan las fotografías y las declaraciones entusiastas de políticos de Bogotá y del extranjero con sombreros artesanales o coloridas telas de belleza nativa. Al final, detenerse unos minutos, mirar el horizonte y dedicar unas palabras a celebrar la alianza entre ali 'junas y wayúu, y a hablar de lo promisorio de los futuros compartidos se ha convertido casi un lugar común.

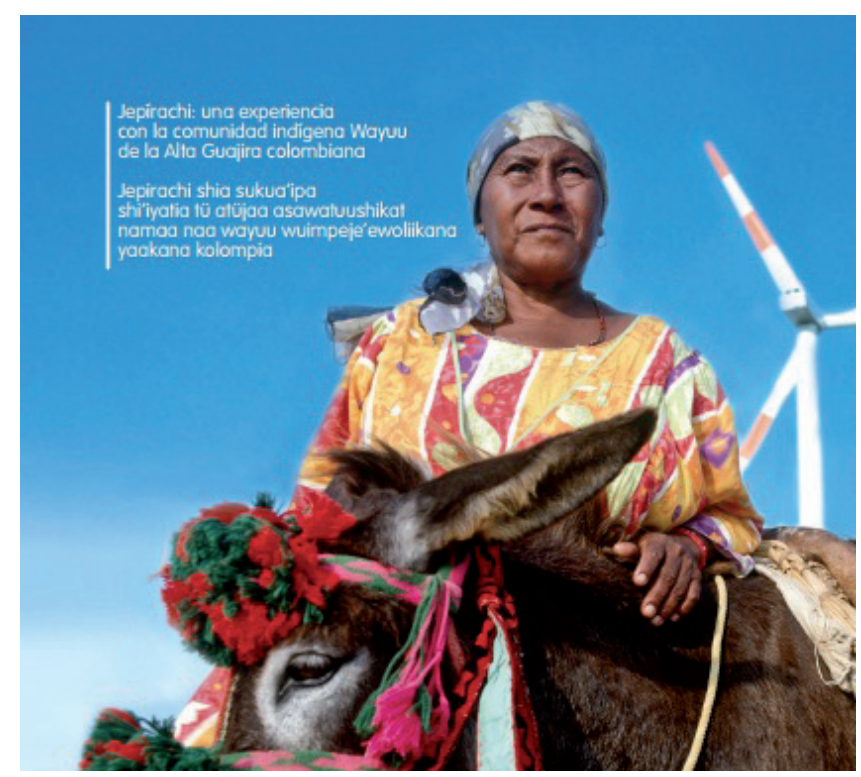

Figura 1. Parque eólico "Jepírachi" (vientos del nordeste en wayūnaiki). La energía del viento. Foto: Captura de pantalla.

Los vientos de cambio soplan con un halo de extrañeza porque, al igual que ocurre con muchas regiones y poblaciones de frontera, la imagen de los Guajiros y de La Guajira para el resto de la sociedad nacional colombiana era la de la diferencia,

representando así uno de los pueblos más numerosos que existen en el país. En Venezuela los wayúu representan el 57,3\% de la población indígena nacional (Censo 2011) constituyéndose así como el pueblo más numeroso. En razón de la especificidad de la experiencia de los wayúu en territorio colombiano, este trabajo se centra en la experiencia de los wayúu en dicho país. 
la hostilidad y la distancia cultural. Una imagen construida a partir de una experiencia histórica caracterizada por una relación de alteridad geográfica y etnográfica y algunas dosis de racismo, exotismo e imaginación. Las ideas de la diferencia, la hostilidad y la distancia cultural que rodeaban a La Guajira y los Guajiros estuvieron combinadas con imágenes y narrativas acerca de las prácticas comerciales que los wayúu implementaron sacándole provecho a la condición fronteriza de su territorio tradicional. A fuerza de negocios hechos con piratas, autoridades coloniales y comerciantes legales e ilegales, los wayúu adquirieron y construyeron, para sí y para su entorno, la imagen de un pueblo guerrero, indomable y situado en las fronteras de la ley.

Para hacer las cosas aun más confusas, los vientos de cambio en La Guajira soplan al mismo tiempo que los wayúu son partícipes y testigos de una violencia que ni en escala ni en crueldad se parece a otras ya conocidas por ellos. Las masacres, los asesinatos selectivos y las amenazas de la historia reciente en La Guajira, perpetrados por paramilitares, narcotraficantes, contrabandistas y otros actores más difíciles de identificar, se hacen con tal intensidad y de tal forma que los wayúu, parecen no saber cómo reaccionar y no saber cómo interpretarla. Una dificultad interpretativa de la violencia que no responde a la falta de experiencia histórica o cultural; los wayúu cuentan con un complejo y sofisticado repertorio de principios y prácticas con los que durante siglos han sabido cómo proceder en la guerra, cómo calcular y hacer efectivas las compensaciones por las faltas, las agresiones, los heridos y los muertos (Nájera Nájera y Lozano Santos, 2009; Molina Ríos, 2013; Polo Acuña, 2012; Guerra Curvelo, 2002).

La primera gran transformación en el pasado reciente se produjo en la década de los ochenta con la llegada a la península de El Cerrejón, una mina de carbón a cielo abierto explotada actualmente por compañías multinacionales y que produce en la actualidad 32,8 millones de toneladas de carbón al año, con utilidades que representan casi un punto porcentual del PIB colombiano y más de la mitad del PIB del departamento. Desde su instalación, la mina implicó una transformación radical del territorio tradicional wayúu y de la región en general, tanto en términos físicos, por la dimensión de su infraestructura, como en términos económicos, por el dinero entregado en concepto de impuestos y regalías. Por su escala, la mina significó también el surgimiento de nuevos órdenes políticos y económicos dominados desde entonces por el proyecto minero. Aún más, la llegada de la mina significó algo acaso menos visible pero de gran importancia: la transformación de la imagen de La Guajira que, como se afirmó, para el resto de la sociedad colombiana hasta entonces era sinónimo de un territorio pobre, apartado y lejano.

La reforma constitucional de 1991 en Colombia, significó la posibilidad de que a los indígenas les fuera reconocido un conjunto de derechos que hasta entonces les habían sido negados y, entre ellos, la seguridad jurídica sobre sus territorios. No obstante, estas medidas enfrentaron resistencias e intereses que en La Guajira se manifestaron bajo la forma de diferentes tipos de emprendimientos económicos, productivos y comerciales, preocupaciones gubernamentales, intereses ambientales, que aun hoy siguen impidiendo a los wayúu la garantía legal sobre sus territorios (CMH, 2010: 131, ver Figura 2). Lejos de ser contradictoria, esta coexistencia entre 
reconocimiento de las identidades y exclusión de esos sujetos otros son características propias del capitalismo tardío que en años recientes se han agudizado con el renovado interés por las tierras indígenas y sus recursos que, en el caso de los wayúu, también tiene que ver con las redes de relaciones que dicho territorio posibilita.

\subsection{Terror, dinero y circuitos de ilegalidad}

Situada en un territorio peninsular de unos $20.000 \mathrm{~km}^{2}$ en la frontera binacional colombo-venezolana, La Guajira se había mantenido relativamente al margen con respecto a las sucesivas olas de violencia que se habían sucedido en otras partes del contexto nacional colombiano desde mediados del siglo XX. Las expresiones de violencia más reciente dieron por terminada esa excepcionalidad y se presentaron bajo una apariencia compleja en la que las violencias de las guerrillas, de los paramilitares, del narcotráfico y del Estado, de los delincuentes comunes y de los delincuentes anónimos, han ido adoptando diferentes tipos de articulación y apariencias diversas.

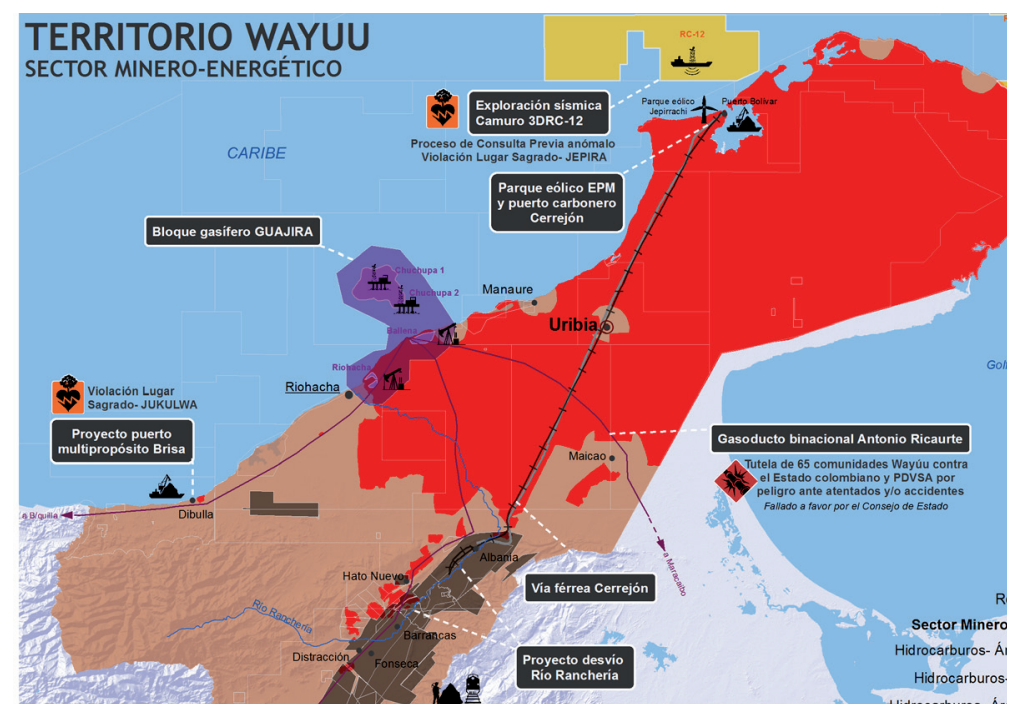

Figura 2. La Guajira, el territorio wayúu y los proyectos minero-energéticos. Mapa: Geoactivismo ${ }^{3}$.

A finales de la década de los ochenta los paramilitares se expandieron en zonas adyacentes al territorio tradicional de los wayúu y en La Guajira en general, a través

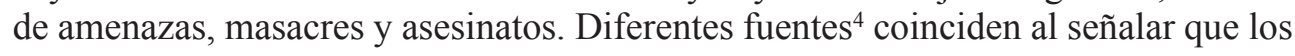

${ }^{3}$ URL: http://www.geoactivismo.org. Consultado: 26 de enero de 2013.

${ }^{4}$ Entre las descripciones que existen acerca de las acciones de los paramilitares en La Guajira de las que resultaron numerosas víctimas wayúu se cuentan las realizadas por las mismas organizaciones indígenas como Fuerza de Mujeres Wayuu (FMW) y Wayuumunsurat-Mujeres tejiendo paz (MUTEPAZ), las elaboradas por movimientos, coaliciones y organizaciones como Verdad Abierta (SF), y el Colectivo de Abogados José A. Restrepo, y las que han sido realizadas por los antropólogos Cortés Severino (2009), Ochoa Sierra (2011), 
paramilitares llegaron a la región atraídos por la localización estratégica de La Guajira en el mapa de rutas de contrabando y narcotráfico, y por ciertas características del Estado en esta zona de frontera. Pero quien se interese por entender las causas de la violencia paramilitar en la zona, sus formas o sus consecuencias, lo primero que encuentra es la abundancia de lecturas y versiones; diferencias que hablan de la lentitud de las investigaciones acerca de la violencia paramilitar, de las diversas lecturas e interpretaciones a que están abiertos los acontecimientos y de las dificultades interpretativas de una violencia cuyas causas, formas y consecuencias parecen depender de quien la describa.

Después de una larga serie de asesinatos y masacres que se produjeron en la región desde finales de la década de los noventa, entre el 18 y 20 de abril de 2004, un comando paramilitar ${ }^{5}$, llevó a cabo la masacre de Bahía Portete, uno de los asentamientos wayúu más importantes de la Alta Guajira (VA, S/F y CMH, 2010). La organización WayuuMunsurat, Mujeres Tejiendo Paz y la Organización Nacional Indígena de Colombia (ONIC) denunciaron que la masacre tuvo como resultado el asesinato de trece personas, la desaparición de treinta y que los paramilitares contaron con la complicidad del ejército ${ }^{6}$. La ACNUR señaló que la masacre produjo el desplazamiento de trescientas personas a lugares como Uribia, Manaure y Maicao, y de otras trescientas a Venezuela.

Exhibiendo un conocimiento detallado de la cultura wayúu, los perpetradores se propusieron transgredir principios y valores morales y éticos, provocar desequilibrios de grandes dimensiones y quebrantar prácticas de duelo cuyo respeto es fundamental para la tranquilidad colectiva $(\mathrm{CMH}, 2010$ : 95). Entre otros, recurrieron de manera deliberada a la violencia contra las mujeres, a la desaparición de los cuerpos, y a la profanación de lugares sagrados. En síntesis, la eficacia de la violencia paramilitar en contra de los wayúu de Bahía Portete estuvo vinculada a las maneras específicas en que los perpetradores buscaron y lograron alterar determinadas estructuras o valores culturales. No intentaré aquí un análisis ni una descripción pormenorizada de la masacre. Más bien, con el fin de entender otros aspectos de la naturaleza de la violencia ejercida en acontecimientos como los de Bahía Portete, intentaré situar este acontecimiento en un sistema más amplio en el que emerge un nuevo orden político y económico en La Guajira y en el que los wayúu y la "cultura wayúu" cumplen un rol fundamental.

y Jaramillo (2011). Medios de comunicación como los diarios El Espectador, El Tiempo, la Revista Semana y los portales Verdad Abierta y La Silla Vacía también han publicado informes e investigaciones sobre el tema. El Estado ha producido recopilaciones y documentos al respecto a través del Centro de Memoria Histórica (2010), y la Fiscalía General de la Nación, a partir de los testimonios de los postulados en las versiones libres efectuadas en el marco de la Ley de Justicia y Paz (Ley 975 de 2005).

${ }^{5}$ Se trata de la Fuerza Contrainsurgencia Wayuu (FCW), perteneciente al Bloque Norte de las Autodefensas Unidas de Colombia, comandada por Arnulfo Sánchez, alias "Pablo" que a su vez estaba bajo las órdenes de Rodrigo Tovar Pupo, alias "Jorge 40".

${ }^{6}$ Informe sobre los hechos de los Alaulayuu de Portete, víctimas de la masacre del 18 de abril del 2004 (CMH, 2010: 158). 


\section{Las mediaciones de memoria y la búsqueda de espacios habilitantes}

Interesado en la dimensión social y colectiva de la memoria, en su obra clásica Halbwachs subrayó que la memoria se estructura a través de "marcos sociales" (1992 [1925]) y se refirió a la memoria histórica como aquella a la que se accede a través de la "lectura", la "escucha", o la "conmemoración" (Halbwachs, 1992: 24) en un proceso en el que las tecnologías, los rituales y los símbolos conmemorativos tienen un rol importante, y en el que se reconoce su dimensión creativa. Más recientemente, trabajos como los de Olick (1999) y Olick y Levy (1997) han definido la memoria como un campo de disputa y negociación.

Frente a las experiencias de violencia masiva del pasado reciente, comunidades, colectivos y organizaciones de víctimas, familiares y activistas en todo el mundo han emprendido iniciativas para interpelar a las sociedades nacionales y a la comunidad internacional con demandas de memoria, justicia y reparación. Para esto, recurren a testimonios, narrativas, performances, monumentos, imágenes, símbolos, arquitecturas, y otras mediaciones de memoria. Con este concepto que retomo del campo de la comunicación (Serrano, 1977; Barbero, 1997[1987]) me refiero a los dispositivos de diversos soportes que abordan las experiencias de violencia masiva con fines como la tramitación ritual o simbólica de un hecho violento y la producción de narrativas que se proponen hacer inteligibles las experiencias para audiencias más amplias. Autores como Bergstrom y Motuz (2012), Landsberg (2004) y Connerton (1996 [1989]), se han interesado en analizar las representaciones que hacen posible compartir las memorias colectivas (lo que aquí entendemos como mediación) trascendiendo el esencialismo y el particularismo de las identidades políticas contemporáneas. Al intervenir entre la experiencia de lo vivido y la construcción de su condición pública, las mediaciones modifican las aproximaciones, las percepciones, y las relaciones con las violencias, las memorias y la justicia. A sus agentes, las mediaciones permiten, o se espera que les permitan, sumarse a una "retórica pública" que trascienda los marcos de sentido en donde se sitúan dichos actos (Bhabha, 2013: 173). Es a través de mediaciones que las víctimas intentan hacer comprensibles los actos de violencia sufridos, como es también a través de mediaciones que se posibilita la legitimación de la violencia ejercida y la construcción social de la impunidad.

Sin limitarse a la cuestión de la memoria y apoyándose en los trabajos de Goffman (1993) sobre la dimensión teatral y performática de la vida social, varios investigadores han recurrido al verbo framing para referirse a la "construcción de significados' en tanto fenómeno activo y procesual que implica la agencia de los sujetos y disputas por la construcción de la realidad (Gamson et al. 1992; Snow et al., 1986; Snow y Benford, 1988). Estos análisis retoman la idea de "políticas del significado" (Hall, 1982) y coinciden en el reconocimiento del significado como algo que es negociado y disputado, entre otros, por actores sociales, Estados y medios de comunicación (Gamson, 1992; Snow y Benford, 1988); negociaciones y disputas que Comaroff y Comaroff (2013[2012]: 2010) denominaron "juego de signos y poder" en el que la memoria aparece como "una representación formulada en un determinado contexto". 
Con la consolidación de los medios de comunicación e información ya como arena de disputa ya como juego de poder, es a través de mediaciones que distintos actores negocian y renegocian narrativas, imágenes y significados con incidencias concretas para la vida de las personas que las involucran. Las formas en que los individuos o las sociedades responden a los actos de violencia masiva tienen que ver naturalmente con los contextos espaciales y temporales en los que se sitúan. En el caso de los indígenas éstas tienen que ver también con historias sedimentadas de relación con los Estados y las sociedades nacionales de las que son parte. Las mediaciones a las que los indígenas están recurriendo en sus prácticas de memoria son extremadamente diversas y están lejos de poder ser reducidas a los esquemas clásicos de las prácticas de memoria, recuerdo y conmemoración, tal y como han sido reconocidas en la esfera de las sociedades nacionales. Así, mientras los wayúu rehabilitan el espacio cotidiano a través de performances de conmemoración como los Yanama en las que en ocasiones "simplemente se está y no se dice nada" (Cortés Severino, 2011), indígenas de otros pueblos, después de largos silencios muy parecidos al olvido, encuentran que llega el momento de destapar memorias de sufrimiento, recurriendo a mapas, calendarios y dibujos y otras mediaciones posibilitadas por los más jóvenes y sus nuevas experiencias de relacionamiento intercultural (Echeverri, 2012).

En 2005, pocos meses después de ocurrida la masacre, un grupo de wayúu en su mayoría mujeres - conformaron la organización, WayuuMunsurat, Mujeres Tejiendo Paz. En alianza con diversas organizaciones, en abril de ese mismo año, la organización promovió un Yanama, un retorno simbólico al lugar, con el propósito de reparación mediando entre el presente y el acontecimiento violento través de prácticas rituales y de duelo y de reconstituir un tejido social que se percibía como "roto". Prácticas de naturaleza similar han sido referidas por Segovia, aunque desde una dimensión más individual en la que, a través del ritual, se interviene "para recuperar la normalidad perdida, una pérdida de normalidad que se corresponde con una amenaza" (2010: 416).

La denominación de Yanama evocaba una práctica tradicional de reunión de varias familias para realizar trabajos comunitarios. Desde entonces, los Yanama se han seguido realizando anualmente adquiriendo una creciente visibilidad, incluso a nivel nacional. Como demuestran los Yanama, muchos indígenas se han convertido en verdaderos autores y gestores de sus propias narrativas, representaciones y versiones de los hechos, gracias a un mayor acceso a los medios de producción comunicativos, dando lugar a una relación más directa con las audiencias. Hablar en primera persona confronta a los sujetos al desafío de hacer inteligible una subjetividad que se supone colectiva, coherente y cohesionada, y de regular las contradicciones que pueden generarse entre las personas tal como son narradas y las personas en sus cotidianidades (Goffman, 2010[1963]: 15)]. Las mediaciones también permiten a los sujetos relacionarse de otras maneras con los pasados traumáticos de violencia, identificar y proponerse nuevos horizontes políticos, e incidir en las formas de relación que mantienen con el resto de las sociedades nacionales. 
Aunque no sin tensiones, las mediaciones están inscritas en el marco de la práctica social en donde a su vez se inscribe la acción política y la cotidianidad. Aunque esto no significa que éstas no puedan ser separadas para efectos analíticos, si implica que tal separación no puede ser concluyente, a riesgo de tomar por el todo la parte; en este sentido cobran sentido los interrogantes formulados por Bhabha en el que experiencia y enunciación, palabras y acción social, se muestran como componente de la misma complejidad: "¿Qué sucede entre el reino de las palabras y el ámbito de la acción social” (2013: 169), “Cómo describimos el circuito de la experiencia a través de la cual se concreta la enunciación?” (2013: 170).

Confrontados a diversos tipos de luchas por una representación equitativa en las esferas públicas, a través de las mediaciones los indígenas se posicionan demandando prescindir de los intermediarios, ser reconocidos como sus propios portavoces, dar por descontada su autenticidad. Planteamientos de estos nuevos actores comunicativos que, insertos en la era de los derechos, resuenan con toda su fuerza emancipadora, pero que inscritos en el campo de la economía política de la cultura develan algunas fisuras. Una mirada atenta a los procesos de producción de las mediaciones de memoria plantea interrogantes con respecto a la transparencia de las narraciones en primera persona así como en relación a proyectos políticos demasiado optimistas con los efectos políticos de la rehabilitación de la palabra y de la posibilidad de elocución en los contextos actuales. Ilusiones que la noción de mediación permite superar al poner en evidencia el carácter construido de esos dispositivos de tramitación del pasado, al reconocer una dimensión dialógica y relacional que trasciende las fronteras interétnicas y los mitos de la autenticidad cultural, y al situar el análisis por fuera de la órbita político-moral de la "legitimidad" cifrada en la combinatoria de derecho-herencia e identidad (Comaroff y Comaroff, 2013[2012]: 208). Por último, ni una mayor capacidad de elocución, ni un mayor acceso a los medios de producción comunicativos, ni una relación directa con las audiencias, significa que las relaciones hegemónicas que caracterizaban la producción de las imágenes y de las narrativas de indígenas y sobre indígenas hayan desaparecido en la esfera de las políticas de la memoria, ya que éstas simplemente se han reconfigurado. Más bien, parece necesario reconocer cierta tendencia a "reforzar los efectos de dispersión de la liberalización política y económica sobre el conjunto de la producción cultural, dejándola sujeta a gran escala a la privatización de la memoria y la particularización del pasado" (Comaroff y Comaroff, 2013[2012]: 2016). En respuesta a esta dispersión los autores subrayan la necesidad de "imaginar como las historias polifónicas del presente" encajan en "estructuras de transformación mayores" (2013[2012]: 2017) en el siguiente punto se presenta la importancia de abordar los puntos de articulación para entender algunos aspectos de las condiciones de posibilidad de dichas estructuras.

\section{Enfrentando las múltiples violencias}

3.1. Un escenario complejo

Las estructuras paramilitares, tal como eran conocidas hasta entonces, se desmovilizaron en el marco de la aplicación de la Ley de Justicia y Paz ó Ley 975 de 
$2005^{7}$ y la violencia generada por la política de seguridad democrática impulsada por Uribe Vélez sufrió un cierto decline con el fin de su mandato presidencial en el 2010 dando lugar a una nueva etapa en el debate público sobre la guerra, y abriendo cierto espacio al debate sobre la justicia transicional en Colombia. A estos elementos se sumó el inicio de las conversaciones de paz entre el gobierno colombiano y las FARC en el 2012. De la grandilocuencia de los acontecimientos no se debe inferir que en varias regiones del país se hayan producido grandes cambios. Aun después de los actos públicos de desmovilización, el paramilitarismo sigue ejerciendo influencia y control político, militar y económico en varias regiones colombianas como La Guajira bajo otras formas, estructuras y denominaciones. Los mecanismos de justicia transicional y las políticas de la memoria de la violencia masiva se enfrentaron a la dificultad de hablar de reparación y de memoria conjugándolas en tiempo presente. Asimismo, las estructuras mafiosas han seguido operando para evitar el desmonte de los beneficios que obtuvieron mediante la violencia.

En la nueva Guajira coexisten empresas mineras, ONG conservacionistas, emprendimientos turísticos, inversores, militares, fuerzas de seguridad, contrabandistas, paramilitares, narcotraficantes, guerrillas y bandas criminales. Se trata de actores que se constituyen y vinculan a través de intrincadas relaciones y flujos en múltiples escalas regionales, nacionales y globales, y entre los que se establece un amplio conjunto de relaciones en el que las tensiones - a veces- se alternan con las alianzas. Esta movilidad permite y garantiza ciertos niveles de convivencia, a pesar de que las diferencias en sus propósitos y formas de acción parezcan profundas y de que entre unos y otros surja o se desmorone la línea que separa las legalidades de las ilegalidades.

Los elementos que han permitido esta convivencia se encuentran en las diferentes articulaciones entre las prácticas tradicionales de la política nacional y regional, las disputas por la representación y la economía política de la cultura. Tal como lo muestra un somero análisis de la masacre de Bahía Portete, el mismo Estado que declara el derecho de las víctimas a la justicia e investiga "casos emblemáticos" de violencia masiva, ha mostrado menos determinación o capacidad frente al desdibujamiento de las fronteras que separan la violencia legítima de la ilegitima, y más condescendencia con los conciertos de las policías (Foucault, 2011[2004]; 1976) legales y legales en la imposición y mantenimiento de un nuevo orden, y un rol activo en el ejercicio mismo de la violencia. Las formas en que algunos integrantes y representantes del Estado actuaron en y en torno a la masacre de Bahía Portete y en las reacciones de la opinión pública nacional frente al acontecimiento, ejemplifica unos modos de articulación entre la política y la legitimidad de la violencia. Al respecto, Jaramillo (2011) ha subrayado que el mismo Estado, participe y cómplice de la violencia masiva, y facilitador de la impunidad y del status quo, aparece hoy como el garante natural y legítimo de la verdad y la reparación.

${ }^{7}$ La normativa fue criticada por la ONU por ser "incompatible" con los principios internacionales, por no abordar la responsabilidad del Estado en varios de los crímenes de paramilitares y por no prever mecanismos que garanticen el desmantelamiento de las estructuras ilegales (ONU 2006). 
Ante la exhibición de impunidad jurídica y pasividad social durante los años siguientes a la masacre de Bahía Portete, es pertinente detenerse por un momento en el rol del Estado en la violencia contra los wayúu y en las reacciones de la opinión pública nacional frente a la violencia. Tres días antes de la masacre, las autoridades wayúu advirtieron del riesgo en que se encontraban y solicitaron protección para sus vidas en comunicaciones dirigidas a diferentes organismos del Estado (El Espectador, 2004). Los wayúu no solamente no obtuvieron respuesta, sino que el Batallón que tenía a cargo la seguridad de la zona fue desplazado al Cabo de La Vela, a unos kilómetros de allí. Ninguna investigación oficial ha podido explicar la facilidad con la que los aproximadamente 50 paramilitares armados y con uniformes del Ejército se desplazaron, burlando los retenes militares de la zona (CMH, 2010: 151); aún más, las declaraciones de varios testigos, y de al menos un paramilitar que participó en los hechos, subrayan la participación directa de miembros del ejército en la masacre (Ibid.). El Estado también fue decisivo en las reacciones del resto de la sociedad nacional ante la masacre; durante los días posteriores distintas oficinas de comunicaciones de las fuerzas de seguridad emitieron comunicados que presentaban la masacre como una confrontación armada entre grupos ilegales o entre grupos wayúu (E1 Espectador, 2004; CMH, 2010: 153-154). Para negar la masacre, trivializar sus causas, y refutar o minimizar los acontecimientos y su impacto, algunos de los organismos del Estado recurrieron a la manipulación de las ideas acerca de la "cultura" refiriendo características supuestamente innatas como su nomadismo o su animosidad.

\subsection{Empresas y mercados}

La expansión de una economía sustentada en el extractivismo en territorios que hasta hace poco eran considerados, distantes y marginales presenta como común denominador su superposición con los territorios tradicionales indígenas o con parte de ellos, la explotación de los recursos naturales a gran escala, la violación de los derechos de las comunidades locales, su desplazamiento y su empobrecimiento. En este despliegue a escala global de las economías extractivas La Guajira no ha sido la excepción. Además de la ampliación de la mina de El Cerrejón hay previstos diversos proyectos como la explotación de la plataforma gasífera y petrolera Bloque Tayrona, el Puerto Multipropósito de la empresa Brisa, la construcción del gasoducto trans-caribeño, y el desembarco de empresas de turismo internacional, que se suman a proyectos ya realizados como el parque eólico Jepírachi y diversos proyectos de conservación, ubicados en el territorio wayúu o en sus proximidades. Aunque en La Guajira no se ha manifestado con los niveles de violencia que se han presentado en otras regiones del país, es preciso subrayar que la expansión de este tipo de proyectos ha provocado en otras regiones asesinatos, amenazas y hostigamientos como respuesta a la oposición de las comunidades locales ${ }^{8}$. La sistematicidad e intensidad

${ }^{8}$ A modo de ilustración puede referirse que en julio del 2008 el Tribunal Permanente de los Pueblos (TPP, 2008) condenó al Estado colombiano por la violación de los derechos humanos de los pueblos indígenas por parte de 43 empresas internacionales que establecieron diversas formas de asociación con paramilitares en diferentes regiones en el país. 
de la violencia masiva derivada de la alianza entre empresas y paramilitares, y el lugar preponderante de las empresas extractivas en el modelo económico nacional de las dos últimas décadas invita a pensar que, al igual que los paramilitares y el Estado, las empresas han identificado y hecho uso de la porosidad de las fronteras entre lo legal y lo ilegal (Garay Salamanca y Vargas Valencia, 2012).

En La Guajira la rentabilidad de las empresas corre de manera paralela y aparentemente desarticulada a las denuncias de las organizaciones indígenas por las transformaciones que llevan a cabo en sus territorios sin instancias de consulta y participación ${ }^{9}$. Desde su instalación en la década de los ochenta El Cerrejón se ha hecho merecedor de varios premios por su Responsabilidad Social Empresarial (RSE). El brillo de estos reconocimientos no debería opacar que la instalación de la mina en 1983 y sus sucesivas expansiones hicieron que numerosas familias indígenas y afrodescendientes fuesen desalojadas y obligadas a despoblar zonas estratégicas para la mina, como Caracolí y El Espinal en 1991, y Tabaco en 2001 (CETIM, 2007). Tampoco debería ocultar que la instalación del Puerto Bolívar significó la invasión de parte del territorio ancestral wayúu en la zona de Media Luna, una zona de gran importancia cultural para los wayúu ubicada a una hora de Bahía Portete, que el ferrocarril dividió en dos el territorio ancestral indígena o que afectó las dinámicas ambientales, sociales y productivas en la región (CGN, 2012) $)^{10}$. Para los wayúu, estás dinámicas han implicado, en mayor o menor medida, discusiones poco transparentes, amenazas, diversos tipos de presión, negociaciones individuales y otros mecanismos de división; en los casos en que se han negado a desalojar la zona, los indígenas han sido víctimas de la destrucción y la quema de sus viviendas por parte de grupos anónimos que, de acuerdo a las denuncias, suelen contar con la participación de las fuerzas de seguridad (CETIM, 2007).

A las críticas y las denuncias de las consecuencias negativas de sus 25 años de operación, la compañía responde subrayando la suma de dinero que entrega por impuestos y regalías, y la implementación de políticas de RSE entre los que se

Denuncias de la misma naturaleza han sido realizadas por periodistas, organismos de derechos humanos, paramilitares desmovilizados, movimientos de víctimas y organizaciones sociales, campesinas, sindicales e indígenas. Entre otros, ver: "La versión de 'Samario' sobre la Drummond y los "paras", Verdad Abierta, 13 de Diciembre de 2010. URL: http://www. verdadabierta.com/component/content/article/36-jefes/2918-la-version-de-samario-sobre-ladrummond-y-los-paras. Consultado: 22-06-2013. "Multinacionales financiaban a paramilitares en Colombia dice ex jefe de AUC", Caracol, 18 de mayo de 2007. URL: http://www. caracol.com.co/noticias/actualidad/multinacionales-financiaban-a-paramilitares-en-colombia-dice-ex-jefe-de-auc/20070518/nota/428732.aspx. Consultado: 22-06-2013. "Fiscal investiga apoyo de multinacionales a paramilitares", El país, 22 de Junio de 2013. URL: http:// historico.elpais.com.co/paisonline/notas/Abril292007/fisca.html. Consultado: 22-06-2013.

${ }^{9}$ Los derechos de consulta y participación han sido reconocidos por sendos instrumentos internacionales (OIT, 1989, Artículo 7; ONU 2007, Artículos 18 y 19) y por las Constituciones nacionales de varios países entre ellos, Colombia.

${ }^{10}$ De acuerdo a cálculos realizados por la Contraloría Nacional, la huella de materiales de la producción carbonífera entre 1990 y 2011 de los departamentos Guajira y Cesar "habrían generado 10.000 millones de toneladas de escombros y residuos rocosos potencialmente contaminantes" (CGN, 2012: 99). 
cuentan, además de los ya referidos, un programa de "visitas ambientales" a la mina para campesinos e indígenas, una boutique en Riohacha en la que los artesanos de los talleres promocionados por El Cerrejón comercializan sus productos, el centro etno-educativo Kamüsüchiwo'u inaugurado en el 2013 y premiado internacionalmente y otros proyectos de carácter ambiental (ver parte 4).

Sin embargo, para los wayúu el impacto "positivo" de la mina es por lo menos relativo; a pesar de que el ofrecimiento de empleo ha sido uno de los principales atractivos, de los 10.000 empleados del complejo, 4.700 son guajiros y sólo el 1\% es indígena (El Espectador, 2014); más allá de los abultados números en impuestos y regalías (la compañía ha pagado \$1461 millones de dólares en regalías en los últimos 25 años), según cifras oficiales el $70 \%$ de la población de La Guajira es pobre y el $30 \%$ vive en la pobreza extrema (DANE, 2011). Es ilustrativo el caso del municipio de Uribia, "capital indígena de Colombia", uno de los tres municipios que más reciben regalías en el país: allí el índice de Necesidades Básicas Insatisfechas es cercano al $100 \%$ y el acceso a alcantarillado y agua potable es menor al $4 \%$ (Benson, 2011). Por último, si bien la mina ha implementado fondos de compensación para los wayúu cercanos a los 5 millones de dólares entre 1982 y 2002, también es cierto que esta suma equivale a la producción de carbón de dos días y medio (Ibíd.). Refiriéndose a la forma en que éstas tensiones se manifiestan espacialmente, una mujer indígena entrevistada por Ochoa Sierra (2011) subrayaba el contraste entre los asentamientos sin servicios básicos situados en las proximidades de la mina y la zona de acceso restringido en donde los empleados de más alta jerarquía cuentan con habitaciones con aire acondicionado, piscina y restaurante.

\subsection{Minería, espectáculo y la creación de un mundo nuevo}

El vínculo entre culturas populares y procesos de construcción nacional ha sido un tópico clásico en los estudios sobre nacionalismo. Desde diferentes perspectivas es una idea relativamente aceptada que los Estados, motivados por visiones románticas, nostálgicas e incluso conservadoras, han recurrido a significados, imágenes y prácticas de la cultura popular como elementos de cohesión nacional a través de acciones de apropiación (Gellner, 2001[1988]: 83), procesos de formalización y ritualización (Hobsbawm y Ranger, 2002[1983]: 10), el uso de estereotipos y visiones estáticas (Pérez Montfort, 2000: 15), e incluso como efecto de su naturaleza sincrética (Edensor, 2002: 35). Ballard y Banks resaltan la importancia de adentrarse en las prácticas discursivas y en la retórica de las multinacionales mineras, y particularmente, en el lenguaje y el ethos que apuntala las relaciones entre las corporaciones y los paisajes locales en los que se involucran" (2003: 292). Tsing, por su parte, subraya el estrecho vínculo entre performatividad económica y performatividad dramática, destacando que las transnacionales no solamente producen espectáculos sino que se empeñan en hacerlo (2000: 118).

Bajo las lógicas contemporáneas de la economía global, las empresas reconocen la importancia de la imagen y su eficacia en el desarrollo económico y se convierten en prolíficos productores culturales (Guss, 2000). Patrocinando unas actividades y no otras, por ejemplo, las empresas promocionan, dan visibilidad y otorgan legitimidad 
a determinados sentidos, estéticas o narrativas de las culturas populares. En el marco del Festival de la Cultura wayuu de Uribia, por ejemplo, El Cerrejón patrocina encuentros de "etnocultura", "palabreros", "sabores y saberes ancestrales" así como exposiciones de artesanías y de medicina tradicional. En estas intermediaciones, las empresas además, utilizan las gramáticas de la cultura popular con el fin de construir para sí mismas sentidos de integración con los contextos en los que se insertan.

Un lugar en donde estas cuestiones pueden ser observadas son las mediaciones, entendidas aquí como objetos que pretenden posicionar determinadas narrativas. Frente a los grandes efectos que pueden tener en su imagen pública la explotación que llevan a cabo, las empresas prestan mucha atención a prácticas corporativas y comunicativas que de distintas formas inciden en dicha imagen. El Cerrejón ha impulsado diversas acciones de este tipo, como programas de investigación e inversión en "mejoramiento de procesos mineros", programas de "rehabilitación de tierras", acuerdos para la "conservación de especies endémicas" y programas de "manejo de eco-regiones estratégicas". Los dispositivos que analizaré persiguen objetivos que pueden ir desde la recaudación de fondos de inversión hasta la recaudación de fondos entre los socios de las ONG internacionales, fondos solicitados a organismos multilaterales, actividades de lobby y actos públicos de cumplimiento de acuerdos internacionales. La noción de mediación opera aquí tanto en el contexto de los procesos de justicia transicional, como en otros campos como la economía transnacional en donde la imagen, la performance y el discurso vienen adquiriendo un rol protagónico. Se trata de mediaciones que aceitan los vínculos entre Estados, empresas, ONG y comunidades y se insertan en espectáculos pues, como afirma Tsing, la "performance dramática" es el "prerrequisito de la performance económica" (2000: 118).

\subsection{Narrativas de la cultura y de la naturaleza en objetos híbridos}

En 2011 El Cerrejón y Conservación Internacional publicaron un libro que documenta el Programa de Rehabilitación de Tierras intervenidas por la actividad minera (Acosta, 2011). Situándose a medio camino entre documento político, herramienta publicitaria, artículo científico e instrumento pedagógico, el libro propone una interpretación de la realidad que está simultáneamente abierta a todas las esferas y que es irreductible a una en particular. Esto posibilita a nivel retórico, que la oposición social a la minería sea un problema comunicacional, que los efectos ambientales de la minería sean una cuestión técnica, que el impacto ambiental cero de la minería de carbón a gran escala sea una cuestión de tiempo, dinero y liderazgo, y que el impacto de las regalías en la reducción de la pobreza una cuestión de coordinación y eficiencia. A nivel político, dicha combinación de registros permite un mensaje de tranquilizante consenso que cobra forma en un libro de una minera transnacional cofinanciado por una organización ambientalista internacional, prologado por el presidente del país, el todo en un escenario en el que la empresa es asiduamente condecorada por sus aportes al medio ambiente.

En uno de los dispositivos se procede a la separación de los ámbitos de las personas y de la naturaleza, la gestión separada de cada uno de ellos, y su reunificación 


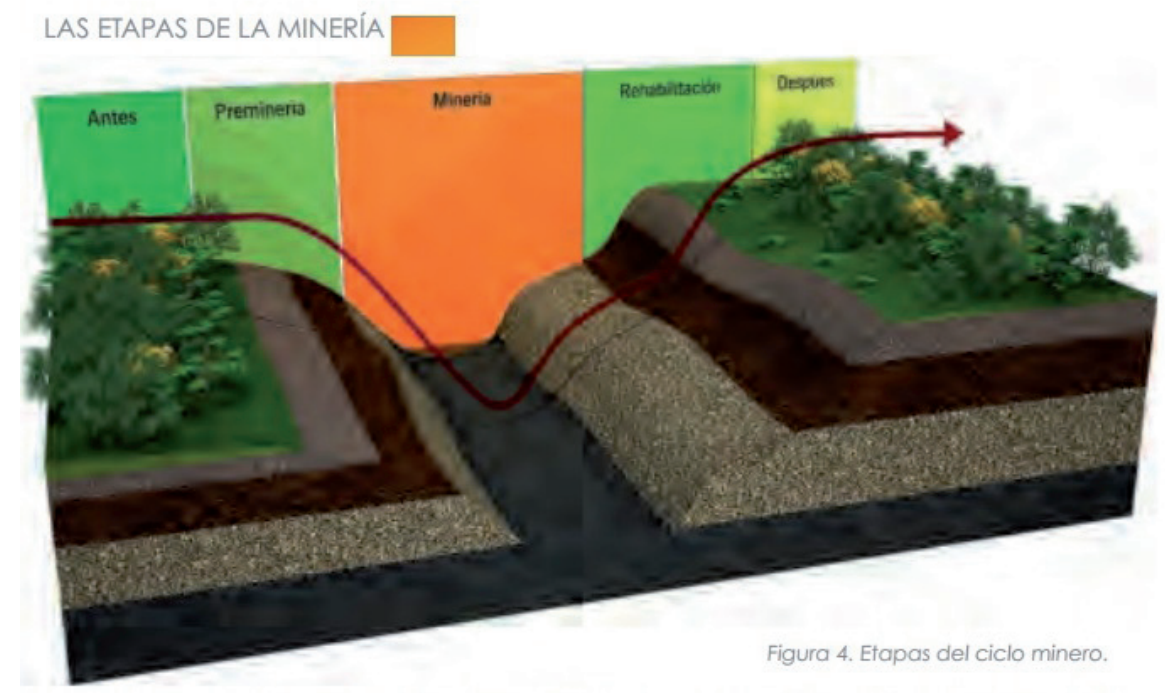

Figura 3. Las etapas de la minería y la Rehabilitación de tierras. Foto: Captura de pantalla. Acosta 2011.

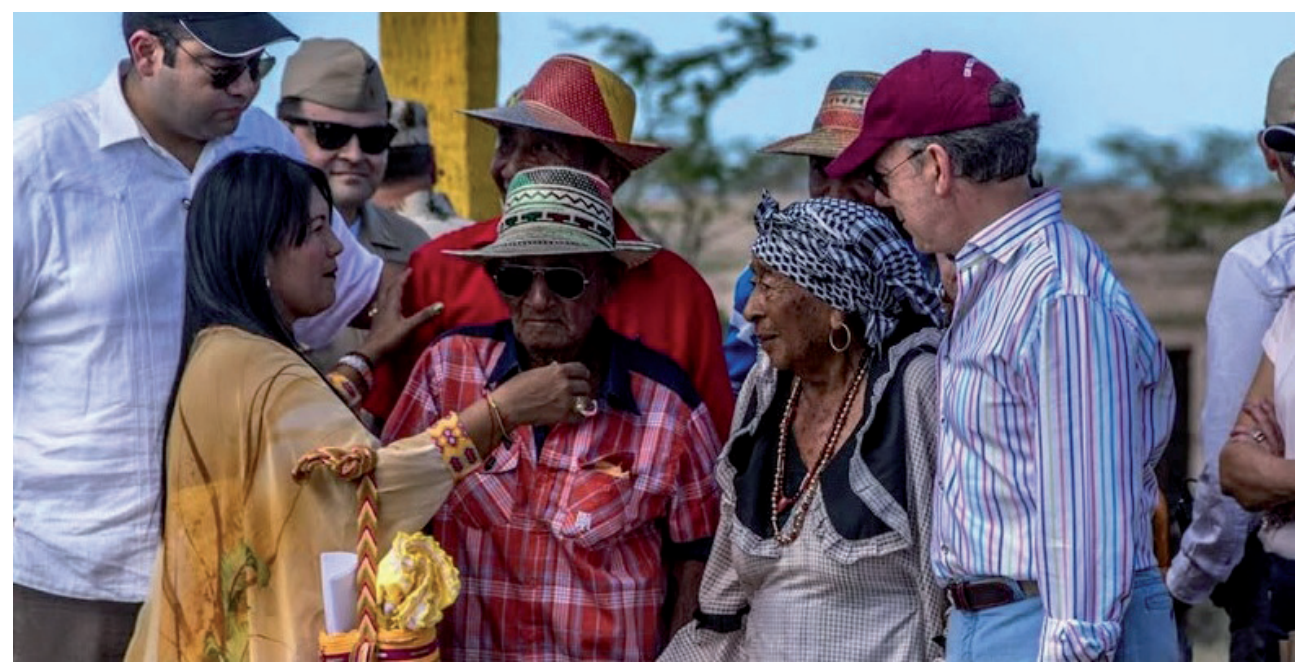

Figura 4. Juan Manuel Santos, presidente de Colombia, indígenas wayúu, representantes de El Cerrejón y militares durante el día de creación del Parque Nacional Bahía Portete Kaurrele.

Foto: Captura de pantalla. Parques Nacionales Naturales de Colombia, 20 de diciembre de 2014¹.

${ }^{1}$ URL: http://www.parquesnacionales.gov.co/portal/en-esquina-norte-de-la-guajira-bahiaportete. Consultado: 11-3-2014. 
posterior. La separación entre los ámbitos se hace a través de recortes de realidad, a los que corresponden escenarios segmentados de diagnóstico y formas diferenciadas de acción, en el que pasivos y activos son gestionados a través de oficinas diferentes (de 'Responsabilidad Social' en el primero, de 'Gestión Ambiental' en el segundo). Ya sin tener que vérselas con las personas, en torno al medio ambiente se implementa una narrativa de la minería como un proceso circular en el que todo parece volver a un estado original prístino, una narrativa en la que a través de técnicas pedagógicas, discursivas y de representación, se postula el impacto cero de la minería, una narrativa, en fin, que sitúa en un extremo inicial a propietarios y usuarios y en el extremo final bosques y áreas protegidas, con una gran diversidad de plantas y animales, capaces de contribuir de manera efectiva con la fijación de carbono y la regulación del ciclo hidrológico para la conservación. En el medio, la máquina mágica del capitalismo tardío que convierte la explotación a gran escala y su paso de las manos de "usuarios" a manos del conservacionismo responsable en una historia en la que todos ganan.

Además de la "rehabilitación de tierras", El Cerrejón viene impulsando desde hace varios años, en alianza con organismos estatales, y ONG conservacionistas como Conservación Internacional (CI) y The Nature Conservancy (NC), proyectos que se proponen la conservación de la biodiversidad y de los recursos hídricos; entre ellos, un proyecto de ecoturismo sostenible en Bahía Portete y una reserva natural para la protección de manglares y especies endémicas; en continuidad con estas iniciativas, el 20 de diciembre de 2014 se declaró la creación del Parque Nacional Bahía Portete Kaurrele. En el discurso de declaración Santos no se hizo ninguna mención a la masacre del 2004.

En su página institucional, la compañía minera informa que el 3 de mayo de 2012 se celebró en la Granja Cerrejón Fundación Indígena una "ceremonia ancestral" con la participación de 300 indígenas wayúu que se reunieron para clamar al "creador del mundo" el envío de lluvia, para lograr la fertilidad de los campos y de los seres humanos (Cerrejón, 2012a). Al encuentro asistieron palabreros, autoridades tradicionales, indígenas arhuacos y zenúes que contribuyeron con sus propios rituales y ceremonias a la grave situación de los wayúu. En sus declaraciones, el coordinador del programa de seguridad alimentaria de la fundación, se manifestó confiado en la eficacia simbólica de los bailes, cantos y músicas tradicionales frente a la necesidad de incrementar el régimen de lluvias y la productividad del sector agropecuario del departamento.

\subsubsection{Gestas ecológicas}

Las organizaciones conservacionistas han identificado "los vínculos que las comunidades mantienen con la naturaleza" como un escenario estratégico para "asegurar un respeto entre interacciones humanas y su conectividad con el medio ambiente" (Conservación para el desarrollo, SF). Como parte de sus actividades de RSE, desde el 2007 El Cerrejón emprendió un proyecto con las comunidades wayúu de Punta Gallinas y Bahía Hondita, en alianza con CI. El proyecto se propone modificar algunos de los patrones de consumo alimenticio y comercialización de tortugas 
por parte de los wayúu de la Alta Guajira en una zona en la que anidan cinco especies. En total, el proyecto involucra a 44 voluntarios y a 99 familias beneficiarias, y en función de los avances que puedan observarse en su cumplimiento de los acuerdos de conservación, los wayúu reciben elementos esenciales para su vida diaria como implementos de pesca y materiales para las artesanías. Según se expresa en uno de los apartes un video producidos en el marco de esta iniciativa (Conservación para el desarrollo, SF), el proyecto reconoce el valor de la biodiversidad para mantener la diversidad cultural del mundo y simultáneamente la necesidad de proveer a las comunidades ingresos provenientes de otros rubros como el ecoturismo.

En el video participa un conjunto de actores en torno a la trama subyacente de una gesta ecológica protagonizada por los wayúu. El video inicia con un mito wayúu sobre la transfiguración de un niño en una tortuga y, por este medio, con la postulación subrepticia de un parentesco primordial posibilitada por la transgresión, tan difundida actualmente, de las fronteras entre las naturalezas y las culturas. Posteriormente se presenta en tono documental, una sucesión de escenarios en donde la comunidad, los consultores internacionales, los inversores, los técnicos, y el Estado hacen su propia lectura del proyecto. El periplo, de agencia poli-céntrica, conduce al observador por las oficinas de los funcionarios estatales, los cafés de reunión de los consultores internacionales, las reuniones comunitarias de los wayúu, los laboratorios científicos, y las playas en donde se encuentran los nidos de las tortugas. Mientras una voz en off describe cómo gracias al proyecto los wayúu desarrollan un "profundo sentimiento ecológico", el video muestra a los wayúu participando en rituales de incorporación de nuevas prácticas, técnicas y saberes: contingentes de wayúu

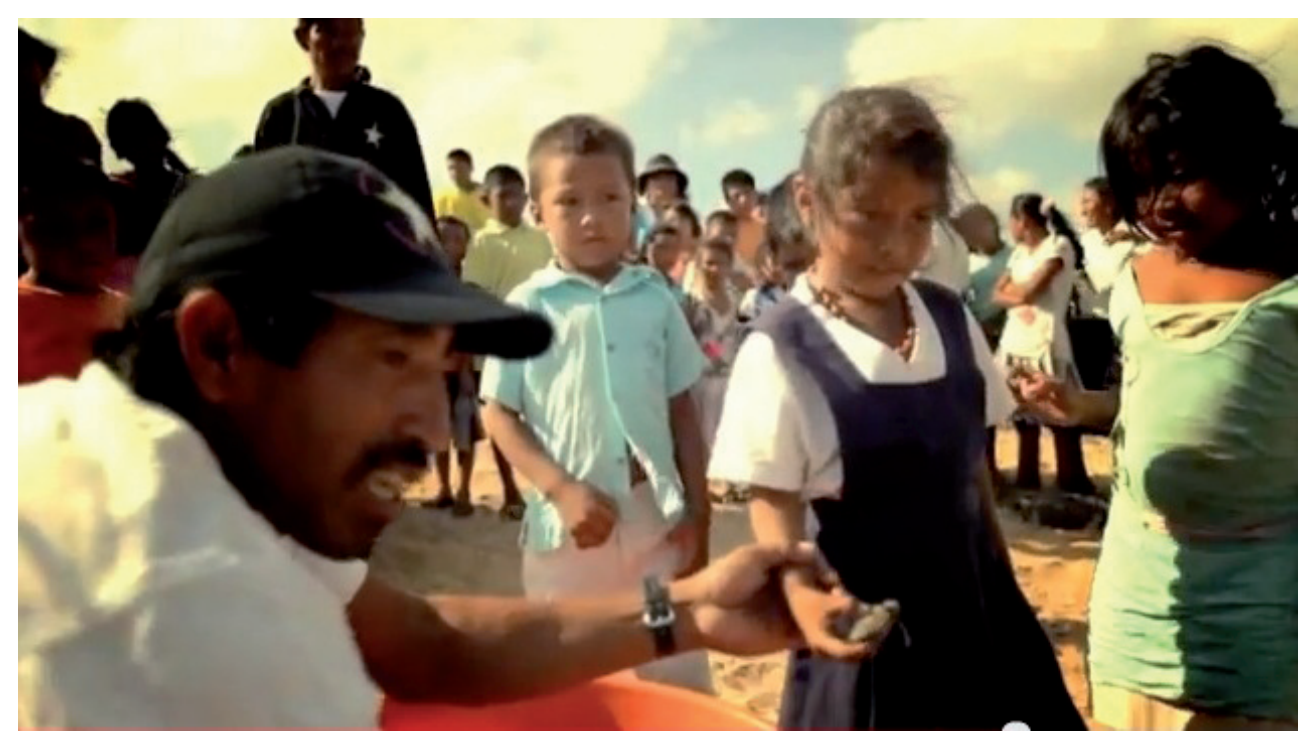

Figura 5. Niños wayúu depositan unas tortugas en el mar.

Foto: Captura de pantalla. Sa'wainrü, Tortuga. Fundación Ecoplanet. 
uniformados de negro y con una gorra de El Cerrejón y organizados en "patrullas nocturnas" que conforman un "ejército de custodia" miden y pesan las tortugas en las playas para su seguimiento, cuidado y protección. La narrativa audiovisual finaliza con una sucesión de planos cerrados sobre las tortugas y luego un plano abierto sobre una fila de niños wayúu que, uno a uno, recibirán las tortugas recién nacidas de las manos de un integrante del ejército de custodia para llevarlas al mar. La performance fue el acto central de la firma del acuerdo que El Cerrejón firmó con la comunidad wayúu de Bahía Hondita y Punta Gallinas con el fin de proteger y monitorear la población de tortugas marinas. Al evento asistieron además de los wayúu, el director de la Autoridad Ambiental, Corpoguajira, el director científico de CI y el gerente del departamento de Gestión Ambiental de Cerrejón (Cerrejón SF).

En este espectáculo del capitalismo tardío los pescadores rescatan tortugas, las tortugas paren con la ayuda de quienes hasta hace poco las consumían, los guardacostas cierras las fronteras al tráfico de fauna protegida, Colombia cumple con sus compromisos internacionales en materia de protección de la diversidad, el financiador ve su dinero bien invertido, los donantes se felicitan por la protección de la diversidad natural y cultural, El Cerrejón demuestra su alto sentido de responsabilidad ambiental, y todos participan de una gesta ecológica protagonizada por comunidades "llenas de necesidades" pero "con un profundo sentimiento de amor por la naturaleza". En ese movimiento esencial del espectáculo que consiste en incorporar a sí mismo todo lo que "en la actividad humana existía en estado fluido para poseerlo en estado coagulado" (Debord, 1995: 35) puede reconocerse a la mercancía aunque ésta se presente como algo trivial.

\subsubsection{Iwo'u yaa: "las estrellas que anuncian la llegada de la primavera”}

Otro de los escenarios en los que la compañía ha desplegado sus acciones de RSE es la cuenca del río Ranchería, la más importante fuente de agua de la región. Postulando la necesidad de un plan de ordenamiento con el propósito de "mejorar" su "gestión sustentable", en el año 2011 El Cerrejón hizo público el proyecto P500 Iwo'u yaa. Agazapado bajo el slogan multicultural tan críptico como poético, el proyecto preveía el desvío de 26 kilómetros del cauce del río, la construcción de una presa, un embalse y la ampliación de la infraestructura portuaria. En algunas notas periodísticas y en reuniones realizadas en comunidades del área de influencia, la empresa destacaba los beneficios previstos en empleos, regalías e ingresos fiscales que se generarían con la ampliación, y los planes y proyectos que la compañía tenía previstos para prevenir, mitigar, corregir o compensar su impacto. En un lugar protagónico aparecía la consulta previa con las comunidades indígenas.

Molinos y pozos de agua, alambres de púas, reces y chivos, tractores y lanchas pescadoras, canchas de fútbol, enramadas con sillas, micro-acueductos y baños, kits escolares, bóvedas para muertos, hilos para artesanías. Demandas y ofrecimientos de mercaderías como estas quedaron registrados en las sesenta y seis "actas" firmadas por la empresa y 103 comunidades wayúu en reuniones que eran descritas por El Cerrejón como reuniones de socialización, de evaluación y "prefactibilidad" y presentadas en los formatos del Ministerio del Interior como 
de consulta previa (Tostón Sarmiento, 2013; Acosta Gamboa, 2013: 37; El Espectador, 2012b).

De manera inédita numerosos wayúu en clara oposición, se organizaron y lograron el respaldo de varios sectores de la sociedad guajira (Acosta Gamboa, 2013). La polémica entre partidarios y opositores dio lugar a intercambios en la prensa local y nacional, en Ministerios y el Congreso Nacional que ilustran el juego de las múltiples caras con las que se intenta viabilizar este tipo de proyectos. Mientras los wayúu organizados y sus aliados proclamaban "al Ranchería nadie lo desvía", los representantes de la empresa afirmaban que el proyecto era uno más entre tantos, que hasta entonces no habían hecho otra cosa que chequeos y pre-consultas, el Ministerio del Interior confirmaba a algunos medios que la empresa había solicitado el inicio formal de la consulta previa varios meses antes (La Silla vacía, 2012).

En noviembre del 2012, la compañía anunció su decisión de posponer los estudios sobre el desvío del río Ranchería, argumentando "las condiciones actuales del mercado internacional del carbón" y añadiendo que tanto los estudios técnicos realizados como la "retroalimentación y aprendizaje recibido por parte de las comunidades durante el proceso", serán la base para el "desarrollo de proyectos futuros" (Cerrejón 2012b); en efecto, en la política contemporánea, la oposición al proyecto es reconvertida en base de prometedoras sinergias gracias a la intervención de la retórica empresarial.

La relación de extrañamiento entre los wayúu y los nuevos contextos tiene poco de excepcional. En todo el mundo, lejos de los viejos esquemas, las grandes corporaciones no exportan valores occidentales a expensas de los valores tradicionales y más que pretender su homogenización, se proponen adaptarse a las diferencias locales (Guss, 2000); una tendencia que se articula a una nueva forma de gobernanza en la que mientras se garantiza una mayor participación y visibilidad pública a los indígenas, se imponen claros límites a sus proyectos de transformación social y se permite la continuidad de las condiciones que reproducen la desigualdad.

\section{Una lectura transversal y la pregunta por las articulaciones: a modo de conclusión}

En los últimos años, los análisis de la violencia han dirigido su mirada hacia los detalles de las texturas de los mundos violentados; situando a hombres y mujeres concretos en lugares y tiempos concretos, algunas de las preguntas han sido reformuladas para poder dar cuenta de las formas diferenciadas en que se ejerce la violencia en función del género, la etnicidad, la edad, las preferencias sexuales, las filiaciones políticas o religiosas, la clase social, y las trayectorias personales. Es de maneras específicas, se postula, que a través de la violencia se afecta las vidas de todos los días, se marcan espacios, se dejan huellas imborrables, se edifican nuevos órdenes sociales; para entender las violencias, las formas en que se ejercen y sus consecuencias, entonces, es necesario detenerse en las especificidades de unas violencias que nunca se ejercen de la misma manera ni son vividas de la misma forma por distintas personas. 
Sin embargo, es necesario complementar estos trayectos con vías alternativas para integrar las unidades de espacios y de tiempos con las que las prácticas de violencia y las políticas de la memoria y la reparación se articulan. Propongo establecer vínculos que permitan conectar acontecimientos de violencia - y memoria - como los de Bahía Portete con otras esferas de la vida social en las que se definen y resuelven una parte importante de las condiciones de existencia de los involucrados; para el caso que no ocupa, la expansión regional de las industrias extractivas y la implementación de determinadas políticas de seguridad, vigilancia, y control.

El origen de la noción de articulación, tal como la utilizo aquí, fue utilizada por Althusser (1974) para referirse a la "unidad compleja" de una formación social determinada en la que existe una multiplicidad de prácticas diferenciadas. En el nivel de análisis de la formación social, existen las instancias económicas, políticas e ideológicas como un sistema de prácticas e instituciones interdependientes entre sí a lo que Althusser se refiere como una articulación, "una unidad de las relaciones de dominación y subordinación" (Resch, 1992: 38). Hall (2005) retomó la noción de articulación en el sentido gramsciano para dar cuenta del no necesario vínculo entre dos planos o aspectos de una formación social determinada, es decir, una clase de vínculo contingente en la constitución de una unidad. Inherente a su noción de hegemonía, la noción de articulación permitió a Gramsci superar las perspectivas reduccionistas y esencialistas de clase, en tanto los sujetos políticos son el resultado de la articulación político-ideológica de fuerzas históricas dispersas y fragmentadas. $\mathrm{Su}$ análisis de la sociedad en torno a la idea de hegemonía reconoce el carácter contingente de la articulación de los elementos y la producción de subjetividades lo que permite superar las definiciones esencialistas de los sujetos. No obstante, vale la pena mencionar que para Hall, éste es un enlace que no se estable casualmente pues existen condiciones históricas en las cuales puede ser o no ser producido. La noción de articulación permite vincular dos o más aspectos de la vida social que, tal como afirma Restrepo en su lectura de las tesis de Hall, "no emanan, directamente, de un sujeto soberano trascendental o de una esencia determinada sino que son contingentes e históricamente producidas y localizadas" (Restrepo, 2004: 31).

En este marco, proponerse una explicación 'totalizante' de la violencia en Bahía Portete parece desacertado, no solamente por las dificultades referidas en la primera parte sino porque las formas de la violencia a gran escala son extremadamente variables, cambiantes y situacionales, y en esa medida, más que las circunstancias resulta pertinente entender las condiciones de posibilidad de dichas circunstancias. Proponerse una lectura a partir del recuerdo parece también insuficiente en razón de que tal variabilidad se da no solo con respecto al acontecimiento sino a las prácticas de memoria y a las mediaciones que se producen en torno al mismo. Sortear estas dificultades en una fórmula que combine la arqueología del acontecimiento con la fenomenología de su recuerdo es igualmente exiguo pues encierra al observador en el acontecimiento mismo ya sea a partir de lo que sucedió, ya sea a través de su recuerdo.

Con el fin de analizar las formas de funcionamiento tanto del acontecimiento como del recuerdo y con el propósito de lograr una comprensión más precisa y a la vez más amplia de las condiciones que hicieron viable, posible y legitima 
la violencia a gran escala, me he propuesto avanzar en dos direcciones. Primero, analizando las formas en que las sociedades indígenas hacen frente a los contextos actuales, en donde la cuestión de la violencia masiva y los mecanismos de verdad, justicia y reparación son un componente esencial pero no el único, y en donde participan activa pero no exclusivamente los wayúu. Segundo, analizando otras esferas de relacionamiento entre los wayúu y otros actores de la sociedad nacional que inciden en la definición de sus condiciones de existencia, con el fin de subsanar la separación existente en los diferentes campos de la política. Frente a esta tarea, la noción de mediación permite identificar algunos de los vínculos que se establecen entre los acontecimientos de violencia y las movilizaciones por la memoria, y la expansión de las empresas transnacionales en los territorios indígenas.

A través de la intermediación de los Yanama, las amenazas actuales e históricas sobre los territorios y sobre las personas son integradas e incorporadas en un mismo registro que se propone lecturas transversales de lo acontecido. En un manifiesto de organizaciones sociales de La Guajira difundido por la organización indígena WayuuMunsurat se afirma: "Nuestros territorios siguen en la mira de las grandes transnacionales, que tratan de arrebatarnos nuestra dignidad y cercenarnos culturalmente de manera lenta y gradual por intermedio de las políticas y la violencia..." (MUTEPAZ, 2008).

Si a primera vista los Yanama pueden ser vistos como actos de resistencia y de desafío a la violencia, algunos elementos vistos en detalle pueden ofrecer otras lecturas. Aún hoy, a más de diez años de la masacre, los desplazados de Bahía Portete no han podido regresar. Situado a 1 hora de Bahía Portete, considerado por los wayúu como "sagrado", Media Luna muestra los rastros de grandes transformaciones por la mina de El Cerrejón y el Parque eólico Jepírachi que, a pesar de los grandes beneficios que se obtienen de ellos, no han implicado que sus habitantes accedan a la luz eléctrica o al agua potable. Para los wayúu, los Yanama también han sido la oportunidad de constatar la consolidación de un nuevo orden en el que persiste la impunidad y se despliegan nuevos actores sobre su territorio.

Los macro-proyectos que en los últimos años han hecho su aparición en La Guajira han implicado la participación de los wayúu en diferentes instancias, entre las que sobresalen la consulta previa y los mecanismos de compensación. Refiriéndose a la forma en que la mina El Cerrejón y los wayúu se han vinculado desde la década de los ochenta, aún antes de que los discursos de la etnicidad y la diferencia cultural cobraran el impulso que adquirirán después, Puerta Silva (2010) señaló el "merecimiento" como uno de los componentes fundamentales del espacio relacional que se constituye entre ambos, un principio según el cual los wayúu buscan hacerse merecedores de los resarcimientos que la compañía debe efectuar.

El Cerrejón no es el único caso en que los promotores del desarrollo han entendido bien lo que parece emerger como un principio de relacionamiento con los wayúu. En un documento institucional del parque eólico Jepírachi, se afirma que, para los wayúu, "la compensación es la base para la solución de los conflictos" (EMP, 2013). Estas ideas están ancladas en una revisión historiográfica que ha identificado la figura del "pago" y su centralidad en la cultura wayúu: 
“el pago constituye un medio y un proceso simbólico y relacional mediante el cual se reconocen los daños materiales y morales de las acciones de una o un grupo de personas sobre el colectivo familiar de la víctima [...] el pago no se limita a un pago material a otro individuo [...] es producto de un acuerdo consensuado además de restaurativo de las relaciones sociales, y expresa lo que para ambas partes constituye el sentido de la justicia” (CMH, 2010: 189).

De tomarse a partir de su forma más básica, entre los espacios relacionales de las empresas transnacionales y aquellos que se establecen en la dimensión de la memoria y la reparación, es posible establecer algunos paralelos. En uno y otro caso, pueden encontrarse la creación y mantenimiento de un círculo compensatorio en el que un agente que perjudica y un agente perjudicado reconocen el daño, acuerdan en la necesidad de reparación del daño y en la forma y fondo de dicha reparación. En uno y otro caso, para los perjudicados simplemente no es posible sustraerse de dicho espacio relacional, en el que quienes efectúan daños están dispuestos a asumir la responsabilidad de sus actos. En uno y otro caso, lo que se discute es la forma en que el daño es reparado y la escala de dicha reparación via indemnizaciones, compensaciones y mitigaciones de impacto. En uno y otro caso, es necesaria la creación de equivalencias entre daños y reparaciones para la eficacia del sistema. En uno y otro caso, no aparece la posibilidad de desmontar las estructuras relacionales que introducen el daño en la lógica de un sistema que lo incorpora.

Los círculos compensatorios en los que ha quedado capturado el desarrollo a través de los proyectos emblemáticos de la economía contemporánea y en el que se está inscribiendo la violencia masiva son parte de tendencias globales: la judicialización de la política, la privatización de la memoria y la cuantificación estandarizada del mundo y sus componentes. Aunque la violencia masiva excede la esfera judicial y la violencia contra los wayúu excede a los wayúu mismos, las políticas de la memoria tienden a encapsular acontecimientos y víctimas segmentándolos de la realidad en la que se inscriben del mismo modo que las consecuencias ambientales del extractivismo, despegadas de sus reales contextos de impacto encuentran su más importante límite en los consejos comunitarios de las Consultas Previas. Es por la vía de la política segmentada, que de los modelos económicos que reproducen la desigualdad, el desplazamiento y la destrucción ambiental parece que solamente pueden discutirse la escala y amplitud de algunos de sus mecanismos compensatorios; es por la vía hipnotizante de las fosas comunes y los cuerpos cercenados que las narrativas de la violencia impiden comprensiones más amplias y a la vez más detalladas de los fenómenos.

En los contextos actuales los wayúu hacen frente a diversos actores que se caracterizan por la ambigüedad en el uso de los recursos legales e ilegales, la transgresión de sus límites con respecto a lo público y lo privado, y las caras múltiples y contradictorias que portan cuando se relacionan con ellos. La capacidad performativa de empresas, ejércitos y agencias del Estado es facilitada por los diferentes usos que hacen de las nociones de cultura y que operan en la esfera de las mediaciones. En esos contextos, se genera una separación cada vez mayor entre la vida cotidiana de la mayoría de los wayúu y la esfera en donde se producen y 
circulan imágenes, discursos, y símbolos que promueven el respeto de las costumbres, incorporan la iconografía local, y que escritas en wayūnaiki sugieren eficazmente el surgimiento de un mundo nuevo de la mano de la economía transnacional. Gracias a su efectividad retórica, esa esfera adquiere cada vez más autonomía y cada vez más visibilidad; y como es más efectiva, y más autónoma y más visible, todos recurren a ella con cada vez más intensidad. Pero ¿de dónde se deriva su efectividad? Los mecanismos compensatorios de las multinacionales de la minería parecen exorbitantes pero en realidad no representan más que un ínfimo porcentaje de sus ganancias. Las políticas ambientales de El Cerrejón son premiadas en foros internacionales como si no hubiesen alterado para siempre y de manera radical el territorio tradicional de los wayúu, segmentándolo, transformándolo y empobreciéndolo; los procesos de consulta previa, libre e informada, al menos en La Guajira y salvo algunas excepciones no han sido previos, ni libres ni informados, y aún en el caso en los que estos se adelantan, no han sido pocas las ocasiones en las que las empresas, el Estado o ambos, implementan mecanismos ilegales para obtener el consentimiento de los indígenas. Bajo la retórica de la expansión capitalista edulcorada con los usos y los abusos de "la cultura", se delega a los wayúu el cuidado de cocodrilos y tortugas y otros roles "estratégicos" en las iniciativas conservacionistas locales, al mismo tiempo que se planean en sus territorios macroproyectos de impacto ambiental incalculable. A la vez y de manera articulada, ni para las víctimas de Bahía Portete ni para cientos de wayúu en toda La Guajira, el proceso de desmovilización de los paramilitares efectuado en el marco de Justicia y Paz ha significado ni paz, ni justicia, ni reparación, pues las estructuras mafiosas y delincuenciales que la perpetraron o sus herederas o sus asociados, bajo distintas denominaciones y de diversas formas, siguen imperando en la región e impidiendo el regreso de las familias desplazadas, desplazando otras, amenazando y matando a quienes luchan contra la impunidad.

Estas paradojas y contradicciones exigen análisis que permitan abordar las articulaciones de campos aparentemente escindidos: entre las políticas del reconocimiento y la violencia étnicamente diferenciada, entre el avance de las empresas transnacionales en los territorios indígenas y una nueva batería jurídica en la que, más que habilitarse derechos, impera la "tiranía de la participación" (Cooke y Kothari, 2001), entre lo que ocurre en la órbita de las representaciones y lo que acontece en todas las demás. Fijándonos en las articulaciones, hemos identificado algunos rasgos de las políticas contemporáneas que requieren de identidades colectivas escindidas entre lo que se es y lo que se significa ser wayúu, y de un tipo específico de repertorios de relación mediante los cuales el "extractivismo" se glosa en los idiomas tradicionales, mientras las poblaciones locales son desposeídas de sus territorios y sus recursos. En el 2012, entrevistado por un diario nacional, un wayúu declaró acerca del proyecto: "Nunca aceptaremos el desvío de un río que nos da la vida. Antes del derecho a la consulta tenemos el derecho a nuestro pensamiento" (El Espectador, 2012a). Estas palabras ejemplifican la forma en que los wayúu pueden sustraerse a las trampas de la política multifacética: anteponiendo el pensamiento y la voluntad a la parafernalia de los derechos culturalmente diferenciados que, más 
que impedir el despojo y la violencia, apuntalan escenarios habilitantes para la hegemonía económico-política de la globalización.

Al hablar de la violencia reciente y de las injusticias históricas, muchos wayúu privilegian la mirada al futuro sobre la mirada al pasado, poniendo más énfasis en las memorias de vida que en las memorias de muerte. Y no es un ejercicio de autoctonía sacrificial y mística o de compasión y misericordia intercultural: al hablar de injusticias históricas, los indígenas están hablando no sólo de justicia para los perpetradores sino también de derechos, de agua, consulta, participación efectiva $\mathrm{y}$, como es el caso de los wayúu desplazados de Bahía Portete, de la habilitación de espacios en los que la vida pueda conjugarse en tiempo presente. Entre dichas mediaciones de memoria y las formas en que los wayúu construyen condiciones de existencias viables para el presente, se abre un escenario para una reflexión que sitúe los acontecimientos de violencia en toda su complejidad.

\section{Referencias bibliográficas}

ACOSTA GAMBOA, Grace.

2013 Iiwo'uyaa, la primavera wayuu... Tesis de grado, Facultad de Comunicación y Lenguaje. Pontificia Universidad Javeriana.

ACOSTA, Ramón.

2011 Hacia la rehabilitación de tierras intervenidas por la minería a cielo abierto. Bogotá: El Cerrejón y Conservación Internacional.

ALTHUSSER, Louis.

1974 Ideología y aparatos ideológicos del Estado. Buenos Aires: Nueva Visión.

BALLARD, Chris y BANKS, Glenn.

2003 "Resource Wars: The Anthropology of Mining", Annual Review of Anthropology, 32: 287-313.

BERGSTROM, Anders y MOTUZ, Alexis.

2012 "Memory, Mediation, Remediation: An International Conference on Memory in Literature and Film", Memory Studies 5: 497-499.

BHABHA, Homi.

2013 Nuevas minorías, nuevos derechos. Buenos Aires: Siglo XXI.

BARBERO, Jesús Martín.

1997[1987] De los medios a las mediaciones. Comunicación, cultura y hegemonía. México: GG.

BENSON, Allison.

2011 "La Guajira y El Cerrejón: Una historia de contrastes", Supuestos, 1 febrero de 2011.

CMH-CENTRO DE MEMORIA HISTÓRICA.

2010 La masacre de Bahía Portete: mujeres Wayuu en la mira. Bogotá: Ed. Semana. 
CGR-Contraloría General de la República.

2013 Minería en Colombia: Fundamentos para superar el modelo extractivista. Bogotá: Contraloría General de la República.

COMAROFF, Jean y COMAROFF, John.

2013 [2012] Teorias desde el sur. Buenos Aires: Siglo XXI.

CONNERTON, Paul.

1996 [1989] How societies remember. Cambridge, Cambridge University Press.

COOKE, Bill y KOTHARI, Uma (Eds.).

2001 Participation: The New Tyranny? New York: Zed Books.

CORTÉS SEVERINO, Catalina.

2011 "Documentando el repertorio: lo audiovisual en las poéticas y políticas del recordar", Revista Colombiana de Antropología 47 (1): 223-247.

2009 "Recolecciones sonoras y visuales de escenarios de memorias de la violencia", Antípoda 9, pp. 165-197.

DEBORD, Guy.

1995. La sociedad del espectáculo. Buenos Aires: La Marca.

ECHEVERRI, Juan Álvaro.

2012 "Canasto de vida y canasto de las tinieblas: memoria indígena en tiempo del caucho". En CORREA RUBIO, François et al. (Comps.). El aliento de la memoria. Bogotá: CNRS, IFEA, Universidad Nacional de Colombia. Pp.: 471-486.

EDENSOR, Tim.

2002 National Identity, Popular Culture and Everyday Life. Oxford: Berg.

FOUCAULT, Michel.

2011 [2004] Seguridad, territorio, población. Buenos Aires: FCE.

1976 Les machines à guérir. Aux origines de l'hôpital moderne. Paris: Architecture+ Archives / Pierre Mardaga.

GAMSON, William.

1992 "The social psychology of collective action" en Morris, Aldon y Mueller Carol (Eds). 1992. Frontiers in Social Movement Theory. pp. 53-76. New Haven, CT: Yale Univ. Press.

GAMSON, William, CROTEAU, David, HOYNES, William y SASSON, Theodore.

1992 "Media Images and the Social Construction of Reality", Annual Review of Sociology 18: 373-393.

GARAY, Luis Jorge y VARGAS VALENCIA, Fernando.

2012 Memoria y reparación: elementos para una justicia transicional pro víctima, Bogotá: Universidad Externado de Colombia.

GELLNER, Ernest.

2001[1988] Naciones y nacionalismo. Madrid: Alianza Editorial. 
GOFFMAN, Ervin.

1993 La presentación de la persona en la vida cotidiana. Buenos Aires: Amorrortu.

2010 [1963] Stigma: Notes on the Management of Spoiled Identity. New York: Simon and Schuster.

GUERRA CURVELO, Weildler.

2002 La disputa y la palabra. La ley en la sociedad wayúu. Bogotá: Ministerio de Cultura.

GUSS, David.

2000 The Festive State: Race, Ethnicity, and Nationalism as Cultural Performance. Berkeley: University of California Press.

HALBWACHS, Maurice.

1925 Les cadres sociaux de la mémoire. París: Librairie Félix Alcan.

1992 "The Legendary Topography of the Gospels", en HALBWACHS, Maurice. On collective memory. Pp. 193-235. Chicago y Londres: The University of Chicago Press.

HALL, Stuart.

1982 "The rediscovery of ideology: return to the repressed in media studies", en GUREVITCH, M. et al. (Ed.) Culture, Society and the Media, pp. 56-90. New York: Methuen.

2005 "La importancia de Gramsci para el estudio de la raza y la etnicidad", Revista colombiana de antropología 41: 219-257 [Trad. Santiago Giraldo].

HOBSBAWM, Eric y RANGER, Terence.

2002 [1983] La invención de la tradición. Barcelona: Crítica.

JARAMILLO, Pablo.

2011 "Reparaciones indígenas y el giro del "giro multicultural" en La Guajira, Colombia”, Revista Colombiana de Antropología, 47(2): 151-171.

LANDSBERG, Alison.

2004 The transformation of american remembrance in the age of mass culture. New York: Columbia University Press.

MOLINA RÍOS, Francisco.

2013 "Venganza y encierro como funciones restauradoras del orden social: un enfoque simbólico-ritual del crimen en la cultura wayúu”, Nómadas, número especial.

NÁJERA NÁJERA, Mildred y LOZANO SANTOS, Juanita.

2009 "Curar la carne para conjurar la muerte. Exhumación, segundo velorio y segundo entierro entre los wayúu: rituales y prácticas sociales", Boletín de Antropología Universidad de Antioquia, 23(40): 11-31.

OCHOA SIERRA, María.

2011 Horror sin nombre. Impacto de la entrada de los paramilitares en territorio wayú. Bogotá: Universidad de los Andes. 
OLICK, Jeffrey.

1999 "Collective Memory: The Two Cultures", Sociological Theory, 17(3): 333-348.

OLICK, Jeffrey y LEVY, Daniel.

1997 "Collective memory and cultural constraint: holocaust myth and rationality in german politics", American Sociological Review 62: 921-936.

PÉREZ MONTFORT, Ricardo.

2000 Avatares del nacionalismo cultural: cinco ensayos. México: CIESAS.

POLO ACUÑA, José Trinidad.

2012. "Disputas y leyes en los conflictos interétnicos en la península de La Guajira (Nueva Granada, 1830-1860)". Anuario Colombiano de Historia Social y de la Cultura 39(2): 69-100.

PUERTA SILVA, Claudia.

2010 "El proyecto del Cerrejón: un espacio relacional para los indígenas wayúu, la empresa minera y el Estado colombiano", Boletín de Antropología Universidad de Antioquia, 24(41): 149-179.

RESCH, Robert Paul.

1992 "Althusser: The Social Formation as a Totality of Instances" en Althusser and the Renewal of Marxist Social Theory. Berkeley: University of California Press.

RESTREPO, Eduardo.

2004 Teorías de la etnicidad. Stuart Hall y Michel Foucault. Popayán: Editorial Universidad del Cauca.

RUIZ GÓMEZ, F., et al.

SF Calidad de vida y salud: un diagnóstico de la zona de influencia de Cerrejón. Bogotá: Ecoe Ediciones.

SEGOVIA, Yanet.

2000 "Interpretación Antropológica del Mal en la Sociedad Wayuu”, Fermentum 29, 407-420.

SERRANO, Martín.

1977 La mediación social. Madrid: Akal.

SNOW, David et al.

1986 "Frame alignment processes, micromobilization and movement participation", Annual Sociology Review 51:464-81.

SNOW, David y BENFORD, Robert.

1988 "Ideology, frame resonance and participant mobilization", International Social Movement Research 1:197-218.

TOSTÓN SARMIENTO, María Paula.

2013 El Río Ranchería. Perdido en el Desierto. Bogotá: INDEPAZ y Reino de los Países Bajos. 
TSING, Anna.

2000 "Inside the economy of appearances", Public Culture 12: 115-44.

\section{Comunicados, notas de prensa, videos y otros}

ACNUR.

2004 "Colombia, desplazamiento indígena y política pública: paradoja del reconocimiento", Ponencia presentada en Consulta regional sobre migraciones indígenas, San José de Costa Rica, IIDH, Mayo 17 de 2006.

\section{CERREJÓN.}

2012a "Indígenas wayuu clamaron por la lluvia, tras el inicio de la primavera", 3 de mayo de 2012. URL: http://www.cerrejon.com/site/sala-de-prensa/archivo-de-noticias/ indigenas-wayuu-clamaron-por-la-lluvia.aspx. Consultado: 13-03-2015.

2012b “Cerrejón pospone estudios sobre la posible desviación del río Ranchería", Oficina de Prensa", Noviembre 8 de 2012. URL: http://www.cerrejon.com/site/sala-deprensa/archivo-de-noticias/aplazamiento-p500.aspx. Consultado: 14-08-2013.

2011 Resumen del proyecto de expansión Iiwo 'uyaa. Para grupos de interés. [En línea]: http://es.scribd.com/doc/103361361/Documento-Cerrejon-Cambio-Cauce-Rio. También [En línea]: http://rio-rancheria.blogspot.com/2011/08/resumen-delproyecto-de-expansion.html

SF. Renovación de acuerdo de conservación de tortugas marinas en Bahía Hondita. Duración 2:49. URL: http://www.cerrejon.com/site/sala-de-prensa/galeria-multimedia/video-liberacion-de-tortugas.aspx. Consultado: 13-10-2014.

\section{CETIM.}

2007 Human rights violations committed by transnational corporations in Colombia Human rights Council-6th session 2007. Item 3: Joint written statement: CETIM and AAJ. A/HRC/6/NGO/8.

\section{CONSERVACIÓN PARA EL DESARROLLO.}

SF Sa'wainrü, Tortuga. Fundación Ecoplanet. URL: http://www.youtube.com/ watch?v=0RqURayB64o. Consultado: 11-12-2013.

EPM-Empresas Públicas de Medellín.

2013 Parque eólico Jepírachi. Tejiendo con el viento. 24 de febrero de 2013. Video Institucional. URL: http://guajirindia.blogspot.com.ar/2013/02/epm-parque-eolicojepirachi-tejiendo.html. Consultado: 20-08-2013.

\section{El Espectador.}

2012a “Los reparos de la Contraloría a Cerrejón”, 2 de noviembre 2012.

2012b "La Guajira despresada", 9 de junio de 2012.

2011 "Trasteo de un río en La Guajira”, 22 de diciembre de 2011.

2004 "La masacre no fue guerra", Bogotá, 6 de junio 2004.

La Silla Vacía.

2012 “Desviación del Río Ranchería, ¿sí o no?”, 20 de agosto 2012. URL: http//:www. lasillavacia.com/historia/desviacion-del-rio-rancheria-si-o-no-35572. Consultado el 25 de Julio de 2014. 
MUTEPAZ.

2008 "Manifiesto de las organizaciones sociales de Riohacha y la guajira con respecto al día de la resistencia de las poblaciones indígenas de Latinoamérica", 6 de octubre de 2008. URL: http://organizacionwayuumunsurat.blogspot.com.ar/2008/10/

OIT. manifiesto-de-las-organizaciones.html. Consultado: 24-11-2013.

1989 Convenio 169 sobre Pueblos Indígenas y Tribales en Países Independientes.

ONU.

2007 Declaración sobre los Derechos Humanos de los Pueblos Indígenas.

2006 "Informe de la Alta Comisionada de las Naciones Unidas para los Derechos Humanos sobre la situación de los derechos humanos en Colombia", E/ CN.4/2006/9, $62^{\circ}$ período de sesiones, 20 de enero de 2006.

TPP-Tribunal Permanente de los Pueblos-Capítulo Colombia.

2008 Dictamen final: Empresas Transnacionales y Derechos de los Pueblos en Colombia, 2006-2008, 30 de julio de 2008. URL: http://omal.info/spip.php?article132. Consultado: 24-11-2013.

VERDAD ABIERTA.

SF "Nunca más la masacre de Bahía Portete". URL: http://www.verdadabierta. com/nunca-mas/nuncamas/3202-la-masacre-de-bahia-portete. Consultado el 15-05-2013.

SF "Especial Guajira”. URL: http://www.verdadabierta.com/gran_especial/guajira/ home.html. Consultado: 13-08-2013.

WAYUU MUNSURAT.

2008 URL: http://organizacionwayuumunsurat.blogspot.com.ar/2008/07/tribunal-permanente-de-los-pueblos.html. Consultado: 13-08-2013. 